\title{
Hannah Arendt e a questão da cultura de massas
}

Thiago Dias da Silva

\section{Resumo:}

O objetivo deste artigo é mostrar outro caminho para a compreensão da problemática da cultura de massas a partir do ponto de vista oferecido pela obra de Hannah Arendt. Colocando a questão nos termos que a autora propõe, percebe-se que a questão da cultura de massas tem raízes mais profundas e é desenvolvimento da relação problemática que a modernidade mantém com a cultura. Para a autora, ao longo da modernidade houve a liberação da atividade do labor para a esfera pública, fato que direcionou o homem para a vida. Tal movimento está em contraposição ao mundo, âmbito da cultura, e tende a absorvê-lo em seu organismo ávido por diversão.

Palavras chave: Arendt, modernidade, cultura, massas 
A partir da constatação de que as massas, e consequentemente sua cultura, não são um fenômeno passageiro, intelectuais conferem à questão da cultura de massas, diz Hannah Arendt, seguindo Harold Rosenberg, uma "dimensão intelectual". Segundo Arendt, a questão passa a ser tratada intelectualmente com seriedade, e neste tratamento muitos críticos chegam facilmente à constatação de que a cultura de massas é uma cultura depravada, oriunda de uma sociedade também depravada. Tal constatação revela a suposição tácita de que, antes do surgimento da cultura de massas, teria existido uma era dourada na qual teria havido uma boa sociedade no seio da qual teria reinado o gosto e o apreço pelas artes, o que teria contribuído para um florescimento das artes e da cultura de valor. Teria havido uma sociedade não depravada que desenvolvera uma cultura não depravada que, portanto, teria maior valor intrínseco se comparada à cultura de massas. Em A crise na cultura, Arendt questiona esta pressuposição tácita de que "nos bons tempos" havia uma arte não depravada, feita por uma sociedade não depravada. A autora nos adverte "contra o anelo fácil de tantos críticos da cultura de massas por uma Idade do Ouro de uma sociedade boa e bem-educada" (ARENDT, I972: 249). Ela nos lembra que a arte moderna surgiu como um grito do artista contra a sociedade enquanto tal e afirma que tal relação - artista e sociedade - é problemática desde o surgimento da sociedade, o que se deu concomitantemente ao nascimento da modernidade. Para Arendt, o problema fundamental se encontra na relação entre a modernidade e as atividades que compõem a vita activa humana.

"Com o termo vita activa, eu proponho designar três atividades humanas fundamentais: trabalho, obra e ação. Elas são fundamentais porque cada uma delas corresponde a uma das condições básicas sob as quais a vida na terra foi dada ao homem” (ARENDT, I998: 7).

\footnotetext{
I Optamos aqui pelos termos "obra" e "fabricação" ao referirmo-nos ao termo work no original de A condição humana, pois cremos que tal opção oferece em relação à tradução brasileira, que optou por "trabalho", uma vantagem ao tratar da obra de arte, o mais mundano dos objetos do "trabalho", que em português é comumente denominada "obra de arte" e não "trabalho de arte". Esta separação do termo em dois, justamente no caso do "mais" work dentre os work, parece-nos problemática e preferimos evitála. Quanto ao termo labor, para o qual aqui optamos por "trabalho", também diferentemente da edição brasileira, justificamos nossa opção pela etimologia que a própria Arendt aponta (Cf. The human condition cap. II nota 3) do termo francês travail, derivado de tripalium, antigo objeto de tortura, o que também vale para o nosso termo "trabalho". Tal opção, cremos, mantém o caráter doloroso da atividade que se encontra na raiz do termo. Tais opções seguem de perto a opção francesa, que para o trinômio labor, work, action, optou por travail, œuvre, action.
} 
Em certos aspectos, segundo Arendt, o homem não se distancia dos animais e compartilha com eles várias características que os condicionam igualmente. Tal qual os animais, os homens estão sujeitos a necessidades biológicas que os movem por grande parte da vida. Na verdade, tudo o que é vivo deve seguir certo ciclo e, na medida em que o homem é um ser vivo, a manutenção de seu organismo requer cuidados adequados às necessidades às quais tal condição o submete. A vida força o homem a entrar em seu ritmo e, enquanto ser que obedece a tal ritmo, o homem é descrito por Arendt como um animal laborans, partilhando esta condição com todo e qualquer ser vivo, animal ou não, mantendo apenas as diferenças específicas que a constituição física de cada espécie exige. Neste sentido, o homem não é em nada diferente de uma árvore, que ao morrer entra no ciclo natural de onde saiu. Enquanto animal laborans, o homem se ocupa exclusivamente de atividades úteis ao funcionamento de seu metabolismo e ao seu desenvolvimento. Tal ocupação, penosa e repetitiva, constitui a atividade do trabalho.

Entretanto, o animal homem tem a peculiar capacidade de deixar para trás certas coisas que ele mesmo fabrica. Promovendo uma enorme violência contra a natureza, o homem retira dela material para construir objetos que não existem objetivamente, mas dos quais ele tem uma imagem mental. Essa imagem não tem realidade na medida em que se encontra isolada na subjetividade de um indivíduo que, porém, é capaz de reificar tal imagem mental, de transformá-la em algo tangível. Perseguindo tal fim, o homem investe contra a natureza - que se deixada por si mesma apenas mantém seu ciclo em funcionamento - com todos os meios que estão ao seu alcance para construir tal objeto, alterando a matéria, forçando-a para produzir o que tem em mente. Em outros termos, o homem é capaz de transformar seu pensamento, que é intangível, vivido apenas por ele mesmo, em algo tangível, visível a todos, com o qual todos os que o cercam estabelecerão alguma relação. Nos termos arendtianos, este processo de fabricação essencialmente humano define o homem como homo faber. Tal atividade, a obra, é capaz de construir objetos que, fruto da violência humana contra a natureza, a ela podem resistir, ou seja, escapam ao seu ciclo infinito e repetitivo de produção e consumo. Tais objetos são fabricados para serem usados pelos homens e não desaparecerem após tal uso, ou seja, para não serem consumidos como os produtos. Para Arendt, a permanência é uma marca dos objetos mundanos, que podem ter mesmo uma possível imortalidade se adequadamente mantidos fora do ciclo da vida. Oferecendo resistência ao ciclo sem fim da natureza, tais objetos concedem certa estabilidade ao homem, tornam-se como que sua casa, pois não são consumidos pela natureza, e são onde o homem se enxerga, na medida em que são a reificação de seu pensamento. Por não serem frutos da vida, dom que o homem partilha com os animais, têm um estatuto humano essencial. 
A ação, por sua vez, decorre do fato de que nenhum homem é igual a outro. Hannah Arendt concebe o nascimento de um ser humano como o início de algo completamente novo e imprevisível, pois as atitudes que este novo ser tomará no mundo não estão de maneira alguma previstas. Nascidos em tempos e locais distintos, levando vidas distintas, os homens são plurais. Desta condição humana, a pluralidade, e do fato de que homens, e não "o Homem", vivem na terra, decorre a necessidade de entendimento entre os homens, que precisam se expressar a outros para serem entendidos. Esta comunicação de seres tão diferentes não é impossível porque "no homem, alteridade (otherness), que ele partilha com tudo o que é, e distinção (distinctness), que ele partilha com tudo o que vive, se torna singularidade (uniqueness), e a pluralidade humana é a paradoxal pluralidade de seres únicos" (ARENDT, 4: I76). Assim, a ação é a atividade essencialmente política, ainda que as demais atividades também mantenham relações com a política.

O conjunto das obras fabricadas pelo homo faber forma o que Arendt chama de mundo e confere uma característica especificamente humana à vida que se encontra entre tais objetos. "Se a natureza e a terra genericamente constituem a condição para a vida humana, então o mundo e as coisas do mundo constituem a condição sob a qual esta vida especificamente humana pode estar em casa no mundo." (ARENDT, I998: I34). Se a vida humana é a que se dá no mundo, o uso dos objetos vincula-se também ao consumo à medida que está vinculado à vida. Tal vínculo fica claro se pensarmos, por exemplo, que um utensílio doméstico qualquer, que permanece após a morte de seu fabricante, é usado na produção ou transformação de bens de consumo, que desaparecem tão logo são consumidos. Arendt considera que este vínculo entre uso e consumo é inversamente proporcional à mundanidade do objeto, que é constituída ainda pela permanência do objeto, que também pode variar. Assim, dentre os objetos que constituem a geografia do mundo, há alguns mais permanentes que outros, mais úteis à vida que outros, mais mundanos que outros.

Então, a obra de arte aparece como objeto do mundo par excellence, pois mais que durar, ela pode ser imortal. Se retirada do ciclo vital e conservada de maneira adequada, é capaz de prender a atenção e comover as gerações futuras por tempo indeterminado, dando testemunho da humanidade que passou por ali e condicionando a humanidade nova que se forma no mundo. Mesmo palavras e ações, que não são capazes de durar sequer até o instante seguinte, quando reificadas em forma de obra de arte, aspiram e podem atingir a imortalidade, pois nesta forma permanecem vivas na memória e são vistas e ouvidas por gerações. $\mathrm{O}$ estatuto do mais mundano dos objetos que tem a obra de arte é ainda reforçado por sua completa inutilidade. Evidentemente, a obra de arte não é fabricada para satisfazer qualquer necessidade vital. Mais, ela não está vinculada a qualquer forma de consumo, ela é completamente independente 
do ciclo vital ao qual se opõe. "Entre os objetos que não ocorrem na natureza, mas tão-somente no mundo feito pelo homem, distinguimos objetos de uso e obras de arte" (ARENDT, I972: 262). Se todos os objetos que formam o mundo possuem uma aparência, que é justamente o que lhes permite estabelecer uma realidade, a obra de arte, mais que isso, é o único objeto fabricado com o exclusivo objetivo de aparecer. Em outras palavras, a obra de arte só existe como aparição, como, phainomenon.

Desta forma, um julgamento adequado à obra de arte deve necessariamente passar pelo sensível, estético, o que transforma a beleza no único critério válido para seu julgamento. Aproximando-se de Kant, Arendt considera que para se apropriar das aparências é necessário se entregar completamente à observação, mas mantendo uma distância do objeto. Distância tanto maior quanto maior é a importância da pura aparência do objeto. Para que se estabeleça tal distância, é condição fundamental o completo desligamento da vida. É necessário estar absolutamente entregue ao mundo, sem que isso tenha qualquer utilidade ou valor além da simples apreciação, do simples uninteressiertes Wohlgefallen kantiano.

Se tomarmos a clássica distinção entre natureza e cultura, percebemos que, na grade conceitual arendtiana, o mundo corresponde à cultura. Tal conceito estabelece a cultura como tudo aquilo que o homem produz escapando da mera condição de ser vivente. Evidentemente, a distinção entre o animal laborans e o homo faber não é absolutamente estrita nos indivíduos ou mesmo na humanidade. $\mathrm{Na}$ prática, uso e consumo se recobrem em vários pontos. Entretanto, é possível pensarmos tais atividades como separadas, especialmente se levarmos em conta a futilidade dos produtos e a permanência dos objetos, a resistência destes ao consumo e sua maior ou menor utilidade. É em torno desta tensão entre permanência e consumo, entre vida e mundo, que Hannah Arendt pensa a questão da cultura de massas, que, veremos por contraste com a antiguidade, é um problema essencialmente moderno.

A cidade antiga, diferentemente da sociedade, se caracteriza pela estrita divisão entre a esfera pública e a privada. A atividade política na cidade antiga se dá na ágora, e este espaço público estabelecido institui relações. Na verdade, qualquer espaço partilhado por mais de uma pessoa o faz, desde que seja vista e ouvida por mais de uma pessoa, i. e. desde que seja comum. "A presença de outros que vejam o que vemos e ouçam o que ouvimos nos garante a realidade do mundo e de nós mesmos”. (ARENDT, I998, 50). Do contrário, tais coisas se fecham na mera subjetividade, tal como a dor física, experiência incomunicável que nos remete para dentro de nós mesmos, para a qual temos dificuldade em criar uma forma adequada de aparição pública. Além disto, a realidade estabelece critérios de julgamento, pensamento, valores, ideias, fornecendo a cada ser humano o seu ponto de vista específico, ou seja, ainda que a realidade seja a mesma, ela não constitui um óbice ao exercício da pluralidade humana, na 
medida em que a relação de cada ser humano com este mundo se dará sempre a partir de seu ponto de vista específico, e nunca de outro. "Viver junto em um mundo significa essencialmente que um mundo de coisas está entre aqueles que o têm em comum, como uma mesa localizada entre aqueles que se sentam em volta dela; o mundo, como tudo aquilo que se encontra entre (in-between), relaciona e separa homens ao mesmo tempo." (ARENDT, I998, 52). Nesta mesa, em volta da qual todos estão sentados, com a qual todos se relacionam, cada um se senta em um lugar distinto e forçosamente a enxerga a partir de um ponto de vista único. Este objeto permanente, por conferir estabilidade ao homem, confere-lhe ainda uma identidade, formada essencialmente, mas não exclusivamente, neste relacionamento com o mundo que o cerca e do qual depende, portanto, tal identidade. Em contraposição a Heráclito, Arendt diz que "os homens, apesar de sua natureza sempre mutável, podem recuperar sua invariabilidade (sameness), isto é, sua identidade, por estarem relacionados ao mesmo lugar em volta da mesma mesa" (ARENDT, I998, I37). Contra a intangível e arbitrária subjetividade humana, erige-se uma objetividade que determina a subjetividade de forma plural. Assim, a ágora grega constitui uma realidade política. Realidade porque compartilhada por todos os cidadãos; política porque nela todos são iguais. As relações que ela impõe entre seus cidadãos são relações políticas, igualitárias, opostas às relações típicas do espaço privado. Nela discute-se a cidade, que é uma realidade, ou seja, espaço comum a todos os presentes.

Por conta deste interesse e da pluralidade envolvida na forma democrática de decisão, o espírito de ágon é presença permanente na ágora. Neste espaço de iguais, cada um de seus membros, ao tentar convencer o outro de suas ideias, busca se distinguir, mostrar com feitos únicos que é o melhor dentre os presentes. Tal singularidade, vimos, é uma das razões da política, pois, se os homens fossem iguais, não teriam a necessidade de falar para serem entendidos, mas, por outro lado, se fossem completamente diferentes uns dos outros, não se compreenderiam entre si, ou aos antepassados. Na disputa política, a exposição da individualidade, aquilo que cada um é, de forma não cambiável, está em jogo. No âmbito das ações, vimos, os homens atualizam sua natalidade agindo de maneira absolutamente singular, desencadeando processos em grande medida imprevisíveis, que, por sua vez, influenciam e determinam outros processos, sendo assim potencialmente eternos e irreversíveis em suas consequências. No caso da política, como a ação é feita à luz da esfera pública e o que lhe confere realidade é ter sido vista por todos que dela participam, ela pode ser julgada, pois se insere na esfera compartilhada por todos, que é capaz de dar critérios para um julgamento.

O homem político, porém, tem um corpo. Apesar de, na concepção antiga, sua atividade ser o exercício da liberdade, ele está submetido à necessidade 
natural que sua condição humana lhe impõe. Para que possa exercer sua digna atividade, é necessário que ele tenha atendidas suas necessidades mais urgentes, aquelas relativas à vida, para então se lançar na atividade livre. Para os antigos, o atendimento de tais necessidades não tem dignidade suficiente para ser exposto no espaço público, devendo ser relegado à esfera privada. É dentro da casa (no oikós, donde oikonomía) que o cidadão se prepara para a vida pública, para a exposição na ágora e para o exercício da mais alta atividade humana, aquela que merece ser vista e ouvida. Entre os antigos (gregos e romanos), estas atividades ligadas à manutenção da casa são relegadas às mulheres e aos escravos, que se dedicam exclusivamente a isso, e que consequentemente não fazem nada de digno, nada de permanente, enfim, que, ao cuidar exclusivamente da vida, apenas trabalham e por isso estão muito mais próximos dos animais. ${ }^{2}$ Sujeitos à dor do trabalho e sempre submetidos ao eternamente renovado esforço necessário para manter a vida, escravos e mulheres na antiguidade não tinham na glória, distinção ou grandeza, os seus objetivos e ideais. Aspiravam, ao contrário, ao alívio da dor, ao prazer e à abundância. Na antiguidade, portanto, é a casa que garante a satisfação das necessidades e libera o homem para a ágora, ou seja, é a esfera privada que prepara o cidadão para sua entrada na esfera pública. É por conta de tal desprezo antigo pela produção, pelo comércio e por outras manifestações do trabalho, que Arendt não concede à cidade antiga o termo sociedade.

Esta distinção fundamental entre público e privado sobre a qual se erige a cidade grega é perdida pelos tempos modernos, pois com o nascimento do Estado-nação, a estrutura política se altera profundamente no ocidente. Esta mudança ocorre porque no interior de um Estado-nação moderno as decisões são levadas a cabo por uma enorme administração de âmbito nacional e não mais na ágora. No âmbito privado, ou seja, dentro de uma casa, a manutenção da vida e a prosperidade são as preocupações comuns que norteiam as medidas tomadas. No Estado moderno, tal qual na família, o fato de que os homens precisam uns dos outros para viver se torna preocupação central, e o espaço onde eles se reúnem para administrar juntos suas condições de vida e de prosperidade se torna o espaço compartilhado. Assim, com o surgimento do Estado-nação ocorre a passagem das preocupações privadas, relativas à vida, para dentro do espaço público, ou, em outros termos, ocorre a liberação do trabalho - antes atividade de escravos e mulheres - para a esfera pública - antes espaço dos homens livres, liberados das necessidades - por meio da nascente esfera social. $\mathrm{O}$ atendimento das necessidades vitais deixa de ser a condição para a ação, para a política, e passa a ser seu motivo.

2 Tal é a leitura feita por Hannah Arendt da controversa consideração de Aristóteles sobre a animalidade dos escravos. Cf. ARENDT, I998: cap. II. 
Neste estágio, a política se funda em uma divisão fundamental entre governantes e governados, estrutura que, mostra-nos Arendt, é basicamente a mesma que encontramos na família, dividida em pais e filhos. Esta estrutura fundamentalmente desigual exige e impõe comportamento padronizado aos governados, pois tem como objetivo prover aquilo de que necessitam os membros enquanto seres vivos. Assim, o comodismo e a preocupação exclusiva consigo, atitudes essencialmente apolíticas, encontráveis no universo familiar da cidade antiga, desenvolvem-se no espaço público sob esta estrutura. Nesta configuração, não se é mais impelido a sair da segurança anônima do espaço privado em busca da arriscada glória pública, na qual o "quem" da ação se revela. Ao contrário, o público se move na direção de manter o homem em sua cada vez mais confortável esfera privada. Cada vez mais reduzidos ao seu elemento meramente animal, os membros da sociedade tendem a unificar as perspectivas em torno de objetivos vitais e, opostos aos administradores, os administrados são concebidos como um todo, um corpo unitário cujos membros têm necessidades e vontades iguais, norteadas pela manutenção da vida e pela prosperidade.

O caráter cíclico e infinito de qualquer processo vital faz com que sua manutenção exija cuidados constantes, sempre renovados, mas visando atender sempre às mesmas necessidades. Ele não apresenta novidades ou diferenças qualitativas ao longo do desenvolvimento de um organismo. Visto que o objetivo do processo cíclico é assegurar a continuidade da vida e o crescimento do organismo, a abundância e o alívio da dor inerente ao trabalho são seus ideais. Tais traços, afirma Arendt, são encontráveis no corpo social que nasce com a modernidade. Fechados no mero ciclo vital, os membros do corpo social estão submetidos a ele e compartilham seus ideais; abundância e prazer. Além disto, nesta configuração, o organismo social é passível de ser observado como um todo que se comporta de maneira determinada ou, pelo menos, determinável (o que explica o sucesso da economia como ciência). Ao dissolver o espaço político, no qual o homem se expõe e se revela, a modernidade o substitui por um espaço social, onde o homem, tal qual escravos e mulheres na antiguidade, apenas produz e consome, contribuindo assim para a manutenção e o crescimento do corpo social, mas nunca se revelando, sempre anônimo, sempre mero membro de certa classe.

Portanto, para Arendt, a era moderna promoveu a liberação do trabalho no mesmo movimento em que deu origem à sociedade, este corpo vivo, orgânico, submetido ao ciclo vital. Se nos lembrarmos que na cidade antiga a política ocorria apesar das necessidades vitais, percebemos o quanto é antipolítica a sociedade, pois nela o homem tende a se fechar exclusivamente na atividade do trabalho, é reduzido a mero animal laborans. Pondo desta forma o problema, surge a pergunta sobre a relação entre o animal laborans e o mundo, com suas coisas permanentes e inúteis. 
"O libelo que o artista, em contraposição ao revolucionário político, atirou à sociedade foi sintetizado muito cedo, no final do século XVIII, numa única palavra, que tem sido, desde então, repetida e reinterpretada geração após geração. A palavra é 'filisteísmo'” (ARENDT, I972: 253).

Quando empregada pela primeira vez nesse sentido, ${ }^{3}$ a palavra mostrava um forte desprezo pelas pessoas de mentalidade meramente materialista, utilitarista, e que, por conseguinte, julgavam inúteis as coisas do espírito, que não trazem qualquer retorno material, que não têm qualquer utilidade. Em geral, a classe burguesa, com sua exuberância material e pobreza espiritual, adequavase bem à palavra, pois só mostrava interesse naquilo que tinha utilidade para a manutenção de sua vida e para sua prosperidade. A questão do filisteu, porém, ganhou complexidade quando esta boa sociedade passou a se interessar pelos bens culturais.

Historicamente, a classe burguesa atingiu sua supremacia social pela fabricação (baseada no trabalho alheio), que envolve muito esforço (não necessariamente o do próprio burguês) ao alterar a natureza para dela arrancar suas riquezas. O burguês, especialmente o do século XIX, enriquece-se ao violentar a natureza para fabricar objetos preconcebidos que, depois de prontos, entrarão no mercado de trocas para cumprir sua finalidade, o lucro. Neste movimento pouco importa se o produto desta fabricação dura ou não - se fabricante de tapetes ou de pães - pois o objetivo seguido se vincula ao par produção-consumo que rege a vida, que rege o animal laborans. Afinal de contas, o objetivo do lucro é a manutenção da vida e o enriquecimento que proporciona a abundância. Assim, se comparada à aristocracia, classe social rival, a burguesia tem pés sujos, pois sua posição está demasiadamente ligada à violenta realidade da produção. Por conta disto, no embate social com a nobreza, seu afã de ganhar dinheiro é visto com desprezo criando a ansiedade por algo que compense tal desvantagem. Em pouco tempo, a burguesia percebe que a cultura é capaz de levar o burguês do chão de fábrica a uma região superior, de luz, onde se situam o belo sutil e o tal espírito de que fala a nobreza. Nesse contexto, a cultura desempenha um papel extremamente importante no jogo da ascensão social. Jogo que determina as características do filisteísmo cultivado, contra o qual a arte moderna vai se rebelar.

O filisteísmo cultivado é marcado, segundo nossa autora, pela preocupação interessada da burguesia com a cultura. Se antes de tal fenômeno o burguês era filisteu por não se preocupar com cultura, pela falta de valor que esta tinha, o fato de o burguês passar a se interessar por ela não o torna menos filisteu -

3 Segundo Arendt, foi Clemens von Brentano, escritor alemão do fim do século XVIII, o primeiro a fazê-lo. 
prático, utilitarista - pois seu interesse é regido exclusivamente pelo grande valor dado à cultura em sua sociedade. Ele não se desvincula da vida para se entregar ao mundo, ambiente para onde se dirige a cultura, reificação do pensamento humano, ambiente no qual se situa o inútil. $O$ burguês não se move na direção do uninteressiertes Wohlgefallen kantiano defendido por Arendt como condição para a devida aproximação da obra artística. Ao contrário, ele canaliza o mundo em função do jogo de ascensão social dentro do qual se encontra. A cultura é deformada, pois é transformada em valor de troca, em moeda dotada de valor no jogo social. Se a cultura constitui o mundo, ambiente potencialmente considerado por todos, que assim forma uma realidade, o caráter evasivo da arte do século XIX é sintoma, aos olhos de Arendt, da desintegração da cultura, que neste ambiente se torna mero falatório, mera conversa fiada, ainda que refinada. $O$ individualismo burguês, sua alienação do mundo, ou seja, o estreitamento de sua visão completamente determinada pelos ideais do animal laborans tornam difícil sua relação com a cultura, que em si mesma não apresenta qualquer utilidade.

Em termos práticos, até o início do século XX, apenas a burguesia fazia parte da sociedade. Consequentemente, visto que a sociedade não atingia a todos, sobravam espaços para a manifestação desta individualidade sufocada pela sociedade. Além dos improdutivos desprezados por Adam $\mathrm{Smith}^{4}$, a mulher, o homossexual, a criança, o louco também estavam excluídos da sociedade. Em tais brechas, a individualidade podia ainda respirar, podia resistir à violenta padronização inerente à sociedade, pois não estava integrada ao ciclo produção-consumo que a caracteriza. Esta boa sociedade, porém, avança à etapa de massas quando absorve as parcelas da população antes excluídas em sua estrutura orgânica acomodadora e deformadora. Nela, tais parcelas são transformadas em classes sociais, com seus respectivos interesses e necessidades. Ao trazê-las para si, ela os integra em sua estrutura familiar e orgânica, deformando-as através do já citado comportamento que ela engendra. Cada classe cumpre sua função e tudo é administrado pelo governo. Se antes havia brecha para a rebelião do artista, na sociedade de massas ela já é calculada e assim neutralizada de antemão. Além disto, vimos, tendo a sociedade sido engendrada com o movimento de liberação do trabalho para a esfera pública, apenas o que está ligado ao par produção-consumo lhe interessa e a absorção das parcelas antes excluídas se dá quando se encontra uma função para elas dentro dos ideais do trabalho. Desta forma, apenas o que está vinculado ao "ganhar a vida" tem algum sentido na sociedade de massas.

O movimento dos trabalhadores, por exemplo, se esforçou em incluí-los no seio da sociedade lutando por melhores condições de vida e se tornando 
justamente uma classe, como qualquer outra. "É a sociedade de massas (...) que emancipa o proletariado colocando o trabalho no primeiro nível das atividades humanas e melhorando consideravelmente as condições de vida dos trabalhadores para que eles possam participar do consumo" (DIAS: 56). Dado o predomínio crescente da sociedade em sua transformação em sociedade de massas, as parcelas antes excluídas se encontram sem saída, pois neste movimento é exclusivamente por meio desta incorporação que elas podem se emancipar. Assim, paulatinamente, todos os estratos da população se veem engajados na luta - antes exclusiva à burguesia - pelo crescimento do organismo e consequentemente os espaços de resistência a ela são apagados. Nesta irresistível absorção, o que era resistência se neutraliza ou passa mesmo a integrar o ciclo orgânico.

Neste contexto, a atividade do homo faber não deixa de ser canalizada também. Vimos que uso de objetos e consumo de produtos se vinculam em vários pontos. Quanto mais ligado ao consumo, ou seja, à vida, menos mundano é um objeto fabricado. Vimos que a fabricação do burguês, por exemplo, ditada pelos valores do animal laborans, é estreitamente vinculada ao consumo. O surgimento da automação - que tende a trocar a força dos trabalhadores pela força mecânica, maior e mais e produtiva que a humana - e a contínua troca das próprias ferramentas da automação por novidades ainda mais produtivas nos provam que este processo se desdobra. Pondo o problema desta forma, surge a questão de como lida a sociedade de massas com os objetos mais inúteis e mundanos fabricados pelo homo faber. Pois, por este prisma, fica evidente que, tendo o trabalho e seus ideais (produção, consumo, crescimento, quantidade...) sido liberados e se tornado a medida das demais atividades da vita activa dentro da sociedade, a arte, que não se encaixa em tais moldes, que não é produtiva, deve ser profundamente alterada para entrar na sociedade de massas. Se a arte moderna foi uma reação do artista - um dos estratos que não estavam incorporados à sociedade - a relação entre este indivíduo - talvez o último - e a sociedade, como já aludimos, é problemática. $\mathrm{O}$ artista faz as vezes de indivíduo, refratário à padronização e à preocupação exclusiva com o crescimento do organismo, interessado em coisas improdutivas, que não entram no processo, que permanecem.

Assim, para Arendt, ainda que apresentem distinções, sociedade e sociedade de massas são no fundo dois momentos distintos de um mesmo fenômeno, enraizado na modernidade. A diferença qualitativa entre os dois momentos existe, mas é muito menor do que supõem alguns intelectuais que compõem o debate no qual Arendt aqui se insere. Desta forma, não faz muito sentido se perguntar - como fazem alguns filisteus cultivados horrorizados com a cultura de massas e seu baixo valor - sobre o caráter depravado de uma cultura feita por uma tal sociedade, que é a mesma, mas em momento diferente. A partir deste ponto de vista, o valor da cultura de massas não está em questão, mas o que importa "é saber se o que é legítimo para a sociedade de massas também o é 
para a cultura de massas, ou, em outras palavras, se a relação entre sociedade de massas e cultura será, mutatis mutandis, idêntica à relação anteriormente existente entre sociedade e cultura" (ARENDT, I972: 249). Hannah Arendt refaz assim a questão e, à diferença dos intelectuais que debatem a cultura de massas e seu valor intrínseco, nossa autora se debruça sobre a cultura na sociedade de massas. ${ }^{5}$

Neste organismo vivo e em constante crescimento que é a sociedade de massas, a classe trabalhadora tem papel fundamental, pois ela encarna o ideal social da abundância, o ideal do animal laborans, já que é de sua atividade que devém a riqueza. Daí o desenvolvimento de uma sociedade na qual o trabalho, desprezado entre os antigos, atinge o primeiro nível das atividades humanas. Esta força social de produção, porém, não pode ser exercida ininterruptamente. Viva, ela precisa de repouso para continuar se exercendo. Tal necessidade biológica confere importância social ao lazer.

Originalmente oposto ao trabalho, o lazer é a forma com a qual se preenche o tempo de maneira livre e desobrigada. Na Grécia, por exemplo, o lazer era a atividade à qual se lançavam os que estavam livres das necessidades da vida. Neste tempo, praticava-se o que havia de mais nobre; de início a guerra, depois a política. Mas face à irresistível absorção do moderno organismo social, nem mesmo o lazer resiste e termina por ser funcionalizado com vistas à produção. Dado seu vínculo ao processo vital, ele passa a ser louvado na sociedade do trabalho. Porém, evidentemente, não se pode crer que o aumento do tempo livre do trabalhador atingido, por exemplo, pelos movimentos trabalhistas, é a realização do antigo sonho humano de liberdade das necessidades vitais ou da dor inerente ao trabalho. Ao contrário, trata-se de sua mais completa derrota, pois mesmo o tempo "livre" é determinado pelo trabalho. Ele não escapa ao binômio produção-consumo inerente ao funcionamento da sociedade, universalizado pela inclusão das massas na sociedade, apenas ganha regras para acontecer, também ele, de maneira produtiva.

5 O título original do ensaio aqui estudado é "The crisis in culture". A nosso ver, a tradução brasileira se equivoca ao traduzi-lo por "A crise da cultura", bem como a francesa, "La crise de la culture". A reformulação do problema feita pela autora, somada à ideia de uma quebra no fio da tradição apontada no prefácio ao conjunto de ensaios do qual este faz parte, indica que, para Arendt, não se trata de uma crise interna à cultura. A crise é muito mais ampla e a engloba. O título do ensaio "A crise na cultura" nos informa que o texto versa sobre os efeitos na cultura de uma crise mais ampla. Cremos que tal leitura é reforçada pelo título do conjunto de textos, "Entre passado e futuro", que inclui ainda um ensaio chamado "The crisis in education", o que exemplifica a amplitude da crise. Se há uma brecha entre o passado e o futuro, é porque o futuro não será uma continuidade do passado que, segundo Arendt, o homem moderno insiste em perder, instaurando assim a referida crise, que atinge também, e talvez preferencialmente, a cultura. 
Além disso, como a produção não vive sem o consumo e vice-versa, a sociedade de massas engendrou uma verdadeira indústria de entretenimento, onde força produtiva é aplicada para a recuperação de força produtiva. Ao se divertir, a parcela da população que em dado momento detém lazer consome a produção da parcela que efetiva sua força de produção. A diversão integra os dois polos centrais da atividade do trabalho, pois o lazer, que já havia sido funcionalizado como recuperação necessária das forças produtivas, agora é funcionalizado também como consumo das forças produtivas exercidas pela indústria do entretenimento. Tem-se, assim, energia circulando dentro da sociedade, tal como em um organismo, ou no conjunto inteiro da natureza.

Um objeto submetido ao lazer entra no metabolismo de um organismo vivo e, tão logo satisfaz a necessidade à qual foi designado, desaparece. Ao se tentar submeter o mesmo objeto para fins de lazer outra vez, ele produz tédio, pois já faz parte do organismo que o consumira. Nesta lógica, é necessário que se trate o objeto como produto de consumo, é necessário que o objeto desapareça e dê lugar a algo novo, que cumpra a mesma necessidade, que reaparecerá em breve. Assim, em completa oposição à durabilidade dos objetos mundanos, a novidade se torna uma exigência dos produtos destinados ao lazer, que desaparecem completamente após cumprirem sua função, ou seja, ao serem consumidos. Eles devem dar lugar a outro produto consumível.

N'A crise na cultura, Arendt elenca três razões pelas quais a obra de arte é o mais mundano dos objetos, a saber: sua durabilidade, sua inutilidade e sua beleza. Nenhuma destas características mantém relação estreita com a natureza, o reino da vida, ao qual o homem está vinculado enquanto animal laborans. Todas essas características se distanciam do homem enquanto vivo e, portanto, nenhuma delas mantém qualquer relação com o homem de massas, guiado pelo princípio biológico, oposto ao mundo, onde se situa a cultura. Entretanto, a sociedade de massas tem se lançado avidamente sobre obras de arte para suprir sua necessidade de lazer. Assim, o homem de massas é, tal qual o burguês, um filisteu, pois se lança à cultura com objetivos sociais.

Porém, diz Arendt, este novo filisteu representa um perigo muito maior à cultura, pois, se a relação com os objetos culturais se dá com vistas ao atendimento da necessidade do lazer, a funcionalização dos objetos passa necessariamente pela massificação, ou seja, pela preparação para a digestão fácil, prazerosa, descompromissada. De fato, a indústria se esforça em difundir para o maior número possível de consumidores seus produtos culturais, pois quanto maior número, maior seu lucro. Mas não lidamos aqui com a democratização da cultura, pois, para serem aproveitados como entretenimento, os objetos culturais não podem ser apresentados tal e qual foram criados. Objetos do mundo não são adequados à satisfação de necessidades vitais, já que não foram criados para a vida, mas para o mundo. E como tal é o objetivo com o qual a sociedade 
se lança sobre eles, forçosamente eles devem ser adaptados a tal função. Além de quantitativamente, os objetos do mundo são massificados também qualitativamente, pois para serem consumidos como lazer, as obras devem ser reduzidas a kitsch, devem ser adaptadas, simplificadas, o que altera profundamente sua natureza. Obviamente, Arendt não critica aqui a distribuição em larga escala de objetos culturais (livros baratos, reproduções de quadros...), mas certo "tipo especial de intelectuais, amiúde lidos e informados, cuja função exclusiva é organizar, disseminar e modificar objetos culturais com o fim de persuadir as massas de que Hamlet pode ser tão bom entretenimento como My Fair Lady, e, talvez, igualmente educativo" (ARENDT, I972: 260). O perigo reside no fato de que o mundo é transformado em produto para consumo, e pouco importa se tal produto é de valor superior ou inferior, se seu destino é a satisfação de uma necessidade e o seu consequente desaparecimento. "Muitos autores do passado sobreviveram a séculos de olvido e desconsideração, mas é duvidoso que sejam capazes de sobreviver a uma versão para entretenimento do que eles têm a dizer" (ARENDT, I972: 260).

Desta forma, Hannah Arendt se distancia dos críticos tradicionais da cultura de massas, que ela alinha aos filisteus cultivados preocupados com o valor da cultura produzida. Entretanto, ela não pode ser vista como defensora da cultura de massas. Na reformulação da questão, percebe-se que Arendt se situa em um plano mais amplo que o dos críticos em geral, o que lhe permite unir os dois lados da discussão. Sendo a sociedade de massas um desenvolvimento da sociedade, por sua vez fruto da modernidade, a relação da cultura em ambas é problemática. A crítica arendtiana se dirige a ambos os lados, pois a raiz do problema está vinculada à modernidade, de onde derivam os dois fenômenos supostamente opostos. A sociedade moderna derrotou por completo a inutilidade da cultura, um de seus pilares, ao lhe conferir um valor, seja no jogo social, seja na matéria-prima para o exercício das forças de produção.

Portanto, para Hannah Arendt, na sociedade de massas a cultura integra o metabolismo do organismo social e é incorporada pelo movimento natural sem fim, violentado pelo homem na construção do mundo. Neste contexto dominado pelo animal laborans, torna-se impossível construir algo que esteja fora do movimento natural, o que torna a expressão cultura de massas uma aberração. Se as massas são justamente o motor do movimento sem fim, que exige novidade constante e que destrói tudo o que toca para satisfazer suas necessidades vitais, o mundo, reino da cultura, essencialmente o que é feito para durar, justamente o oposto do movimento, é particularmente ameaçado pela sociedade de massas. Tendo o homo faber sido subjugado pelo animal laborans, o mundo foi engolido pela natureza, o homem se entregou à sua animalidade, pois encontra valor exclusivamente naquilo que compartilha com tudo o que é vivo. O desinteresse das massas por cultura é um risco para ela porque as massas se desinteressam 
fundamentalmente pela permanência, essência da cultura e ainda assim dela se apropriam. Sendo a sociedade essencialmente utilitarista, ela não transcende as funções vitais de seu metabolismo, ela se torna essencialmente imanente, e "o perigo é que tal sociedade, deslumbrada com a abundância de sua crescente fertilidade e encerrada no brando funcionamento de um processo sem fim, possa não ser mais capaz de reconhecer sua própria futilidade" (ARENDT, I998: I35).

\section{Referências bibliográficas.}

Arendt, H. The crisis in culture: its social and its political significance, IN: Between past and future. New York: Penguin Books, 2006.

A crise da cultura: sua importância social e política, IN: Entre o passado e o futuro. São Paulo: Editora Perspectiva, I972.

The human condition. Chicago: The University of Chicago Press, I998.

The gap between past and future, IN : Between past and future. New York: Penguin Books, 2006.

Adler, L. Nos passos de Hannah Arendt. Rio de Janeiro: Record, 2007.

Dias, M. Hannah Arendt: culture et politique. Paris: L'Harmattan, 2006.

Finley, M. Democracy, ancient and modern. London: The Hogarth press, $2^{\circ}$ ed. I985.

Gombrich, E. The story of art. London: Phaidon, I995.

Hobsbawn, E. Era dos extremos: o breve século XX. São Paulo: Gia da Letras, 2001 .

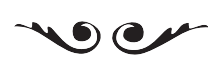

Thiago Dias da Silva é graduanda em Filosofia pela USP.

E-mail: thdiass@yahoo.com.br 